\title{
EFFECT OF FLYER SPEED ON YARN BREAKAGES IN PRODUCTION OF JUTE YARN
}

\author{
${ }^{1}$ A. K. M. Mahabubuzzaman, ${ }^{2}$ Md.Osman Ghani Miazi and ${ }^{3}$ Ayub Nabi Khan \\ ${ }^{1}$ Department of Spinning, Mechanical Processing Division \\ Bangladesh Jute Research Institute (BJRI), Manik Mia Avenue, Dhaka, Bangladesh. \\ ${ }^{2}$ Mechanical Processing Division \\ Bangladesh Jute Research Institute (BJRI), Manik Mia Avenue, Dhaka, Bangladesh. \\ ${ }^{3}$ Department of Textile Engineering, Southeast University, Banani, Dhaka, Bangladesh. \\ E-mail: tahminamita@yahoo.com.au,dr.mahabub@hotmail.com
}

\begin{abstract}
In Bangladesh, jute mills are producing conventional yarns heavier than 275 tex. These are used as hessian, sacking, carpet backing cloth etc. For diversified uses of jute it is most essential to produce medium count yarn of 241 to 275 tex. In this regard, slip draft spinning machine has been studied. This machine is capable to produce yarn of 241 to 280 tex at flyer speed of $2900 \mathrm{rpm}$ to $4850 \mathrm{rpm}$. But there is a relation between flyer speed and yarn breakages of the machine. In addition spinning efficiency of the machine also depends on the yarn breakages. Through a series of experiment, a relation has been established between flyer speed and yarn breakages of the experimental machine for production of jute yarn. From the experimental observation, it shows that for production of 241 tex jute yarn 4700 rpm flyer speed is the most suitable speed and $4800 \mathrm{rpm}$ flyer speed is the most suitable speed for production of 275 tex jute yarn. In addition productivity of the machine also maximum at that flyer speed of the machine. In this experimental study, it was found that at $4850 \mathrm{rpm}$ it was very difficult to spin yarn due to its random breakages. That consequently lowered the productivity. Therefore, it is necessary to select proper flyer speed for the production of yarn of particular linear density (tex). It was also observed that the number of breakages increased with the increase of flyer speed. At 2900-rpm flyer speed, the yarn breakage was 0.8/ spindle-hr and at $4850 \mathrm{rpm}$ the yarn breakages is 3.5/spindle-hr. for producing 241 tex jute yarn. Almost all jute mills of Bangladesh have been slip draft spinning machine. Using proper flyer speed, which was found from the experiment, can use the machine in production of medium count jute yarn. The produced yarn can replace the synthetic/manmade fibre in the world textile market.
\end{abstract}

Key Words: Spinning, Tex, Productivity, yarn and Breakages.

\section{Introduction}

Jute is a natural cellulosic bast fibre. It is a textile fibre of good spinnable character. Now a days Jute, textile earning $12 \%$ of total foreign currency for Bangladesh, is facing tough compatibility from cheap synthetic fibres [5]. Hence for the survival of this environment, friendly fibre, its is necessary to diversify the use of jute by making new products with raw and modified Jute, Usually coarser yarns and manufactured from Jute fibre but the flyer spinning. Ring spinning, Wrap spinning and centrifugal spinning, which we usually used to spin jute yarn, are used for medium count yarns [1].

Bangladesh earns about $70 \%$ of its foreign currency by exporting ready-made garments. However, the lion's share of earned foreign currency is spent for importing 95\% of required fabrics for garments. Only $5 \%$ of required fabrics are produced locally for ready-made garments [7]. To overcome this high competition it is necessary to produce quality jute yarn by slip draft spinning frame. Through this machine, it may be possible to spin quality jute yarn, which can be used for diversification of jute such as shopping bag, furnishing fabric, decorative fabrics, finer fabrics etc. As a result, jute fibre may be used in the production of fabric that may further enhance its uses in various fields of textiles. Productivity is an important factor for any production-oriented industry. In this view for achieving maximum productivity, it has been necessary to determine the optimum parameters. The idea of this study was to determine the flyer speed and yarn breakages for maximum productivity of jute yarn 241 and 275 tex from the slip draft spinning frame. 


\section{Materials and Methods}

BWB (Bangla white B) grade of jute fibre was taken as the raw material for the experiment. Fibre was piled with required emulsion and kept for 48 hours for maturation. Then the fibre was processed through Breaker card, Finisher card \& the conventional drawing line $\left(1^{\text {st }}, 2^{\text {nd }} \& 3^{\text {rd }}\right)$ for spinning yarns of 241 and 275 tex. The $3^{\text {rd }}$ drawing sliver was processed for spinning into yarn with different flyer speeds in the slip draft spinning frame. In the spinning department, the slip draft-spinning machine of forty flyers was used in the experiment. James Mackie \& Sons Ltd. of Ireland manufactured the original machine (flyer type). In the flyer type spinning frame, the twist is inserted into yarn by the effect of flyer speed.

\subsection{Effect of flyer speeds on productivity on produced yarn}

The flyer speed has various effects on productivity. It is directly related to the yarn tension during the winding of yarn on a bobbin [4]. Spinning tension and flyer speed are two closely related parameters. It has been known from the earliest days of spinning, higher flyer speed increase the yarn breaks during spinning.

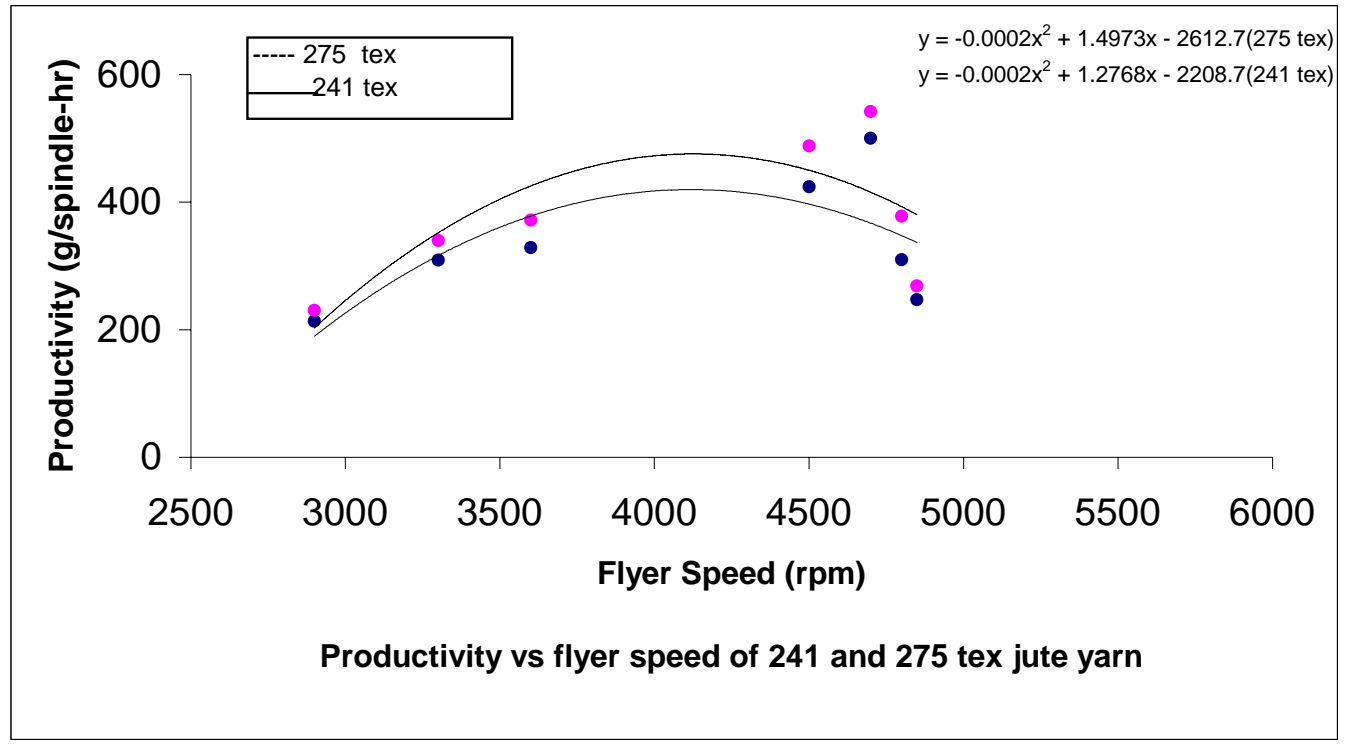

Fig. 1 Productivity vs flyer speed of 241 and 275 tex jute yarn

Flyer speed for the production of 241 tex jute yarn is found to be $4700 \mathrm{rpm}$ whereas for 275 tex jute yarn it is also $4700 \mathrm{rpm}$ for maximum productivity. The results are plotted in figure 1. Production of yarn through higher speed than the optimum flyer speed increased the number of yarn breaks which reduces the production rate. On the other hand lowering the speed automatically lowers the productivity [3].

An equation has been formulated between the flyer speed and productivity of the machine. The relationship is as follows: $\mathrm{y}=-0.0002 \mathrm{x}^{2}$ $+1.2768 \mathrm{x}-2208.7$ for 241 tex and $\mathrm{y}=$ $0.0002 x^{2}+1.4973 x-2612.7$ for 275 tex jute yarn. Where $\mathrm{x}$ is the flyer speed (rpm) and $\mathrm{y}$ is the productivity (g/sp.-hr). The developed equations are valid for $\mathrm{x}=2900 \mathrm{rpm}$ to 4850 rpm.

2.2 Effect of flyer speeds on no. of yarn breakages on produced yarn

In this experimental study it was found that at $4850 \mathrm{rpm}$ it was very difficult to spin yarn due to its random breakages. That consequently lowered the productivity. So it is necessary to select proper flyer speed for the production of yarn of particular linear density (tex). It was also observed that the number of breakages increased with the increase of flyer speed (fig. 2).

Initially it increased slightly up to optimum flyer speed. After the optimum flyer speed the breakages rate of yarn was higher and it followed the mathematical relationship of 
polynomial type. For 241 tex it followed $\mathrm{y}=$ $1 \mathrm{E}-07 \mathrm{x}^{2}+8 \mathrm{E}-05 \mathrm{x}-0.3154$ for 241 tex and for 275 tex it followed $y=2 \mathrm{E}-07 \mathrm{x}^{2}-0.0003 \mathrm{x}$ +0.2063 for 275 tex' Where, $y=$ number of yarn breakages and $\mathrm{x}=$ flyer speed (rpm). The equations are valid for $\mathrm{x}=2900 \mathrm{rpm}$ to $4850 \mathrm{rpm}$.

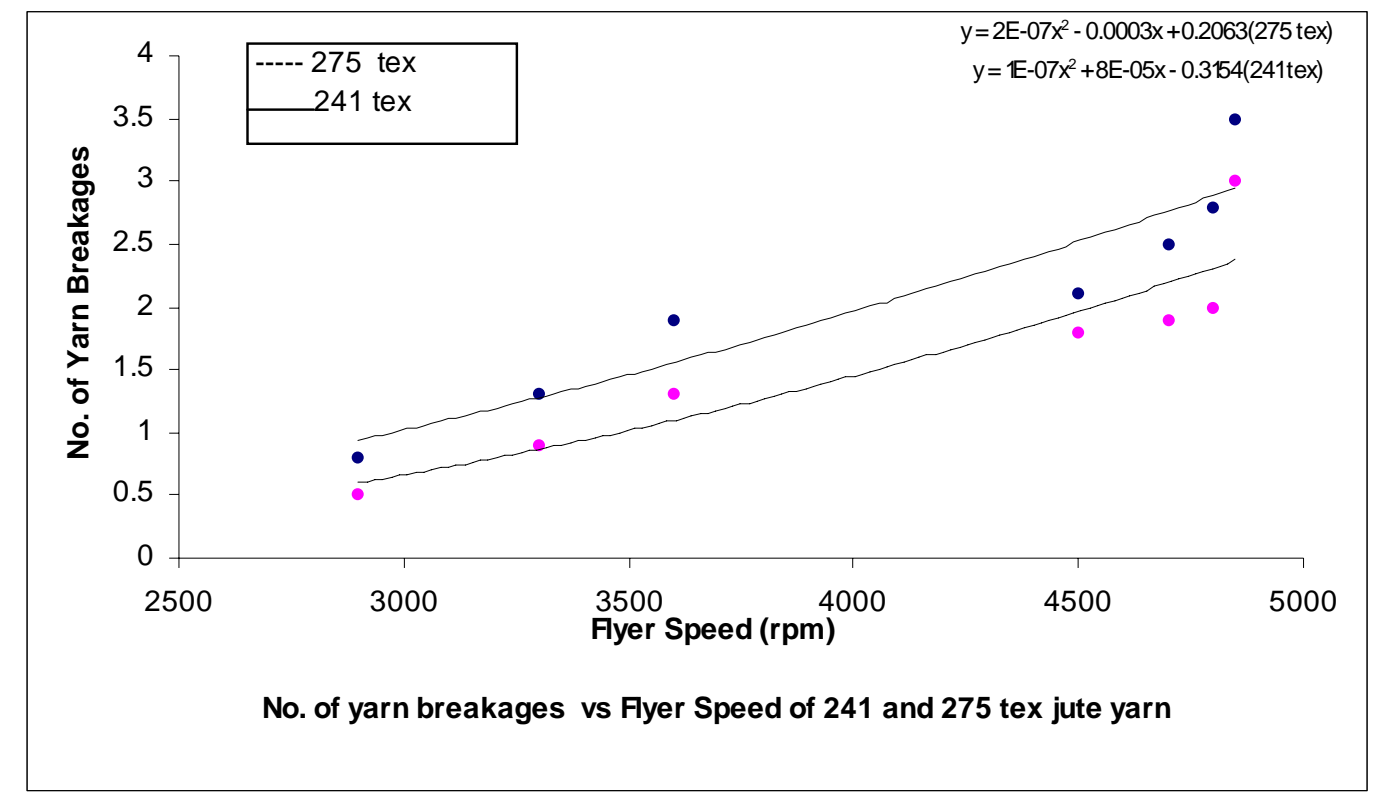

Fig. 2 No. of yarn breakages vs. Flyer Speed of 241 and 275 tex jute yarn

\section{Results and Discussions}

BWB jute fibre was processed through different flyer speeds at fixed draft of 11 along with different levels of twist to spin
241 tex and 275 tex [2]. After spinning, the physical properties of the yarn were measured.

Table 1 Physical properties of 241-tex jute yarn at different flyer speed in Slip Draft spinning Frame

\begin{tabular}{|c|c|c|c|c|c|}
\hline $\begin{array}{c}\text { Flyer Speed } \\
(\mathrm{rpm})\end{array}$ & $\begin{array}{c}\text { Load at Break } \\
\text { (Kgf) }\end{array}$ & $\begin{array}{c}\text { Strain at } \\
\text { Break (\%) }\end{array}$ & $\begin{array}{c}\text { Tenacity at } \\
\text { Break } \\
(\mathrm{N} / \mathrm{Tex})\end{array}$ & $\begin{array}{c}\text { Textile } \\
\text { Modulus } \\
(\mathrm{N} / \mathrm{Tex})\end{array}$ & $\begin{array}{c}\text { Quality } \\
\text { Ratio (\%) }\end{array}$ \\
\hline 2900 & 3.060 & 1.905 & 0.124 & 6.661 & 95.683 \\
\hline 3300 & 3.100 & 2.023 & 0.125 & 6.293 & 96.648 \\
\hline 3600 & 3.040 & 1.983 & 0.123 & 6.620 & 96.288 \\
\hline 4500 & 2.890 & 2.259 & 0.117 & 5.221 & 89.859 \\
\hline 4700 & 3.130 & 1.984 & 0.127 & 6.663 & 97.596 \\
\hline 4800 & 3.040 & 1.648 & 0.123 & 7.697 & 92.436 \\
\hline 4850 & 2.530 & 1.707 & 0.102 & 6.189 & 77.462 \\
\hline
\end{tabular}

Table 2 Physical properties of 275-tex jute yarn at different flyer speed in Slip Draft spinning Frame

\begin{tabular}{|c|c|c|c|c|c|}
\hline $\begin{array}{c}\text { Flyer Speed } \\
\text { (rpm) }\end{array}$ & $\begin{array}{c}\text { Load at Break } \\
\text { (Kgf) }\end{array}$ & $\begin{array}{c}\text { Strain at } \\
\text { Break (\%) }\end{array}$ & $\begin{array}{c}\text { Tenacity at } \\
\text { Break } \\
\text { (N/Tex) }\end{array}$ & $\begin{array}{c}\text { Textile } \\
\text { Modulus } \\
\text { (N/Tex) }\end{array}$ & $\begin{array}{c}\text { Quality } \\
\text { Ratio (\%) }\end{array}$ \\
\hline 2900 & 3.210 & 2.219 & 0.103 & 5.198 & 88.368 \\
\hline 3300 & 3.200 & 2.360 & 0.110 & 4.661 & 87.851 \\
\hline 3600 & 3.200 & 2.299 & 0.113 & 4.981 & 87.306 \\
\hline 4500 & 3.440 & 2.553 & 0.122 & 4.886 & 93.971 \\
\hline 4700 & 3.380 & 2.239 & 0.120 & 5.406 & 91.825 \\
\hline 4800 & 3.540 & 2.514 & 0.124 & 5.016 & 96.463 \\
\hline 4850 & 3.100 & 2.298 & 0.110 & 4.821 & 84.682 \\
\hline
\end{tabular}


Table 3 Productivity of 241 tex jute yarn at seven different flyer speeds (Draft 11, Twist 189 tpm)

\begin{tabular}{|c|c|c|c|c|c|c|c|}
\hline \multirow{2}{*}{$\begin{array}{c}\text { No. of } \\
\text { Exp. }\end{array}$} & \multicolumn{6}{|c|}{ Yarn productivity ( g/ spindle -hr ) through different flyer speeds ( rpm ) } \\
\cline { 2 - 8 } & 2900 & 3300 & 3600 & 4500 & 4700 & 4800 & 4850 \\
\hline 1 & 109 & 135 & 188 & 208 & 260 & 205 & 170 \\
\hline 2 & 105 & 130 & 190 & 210 & 253 & 211 & 160 \\
\hline 3 & 107 & 122 & 175 & 185 & 245 & 210 & 155 \\
\hline 4 & 103 & 140 & 185 & 195 & 250 & 215 & 140 \\
\hline 5 & 110 & 130 & 190 & 210 & 255 & 217 & 165 \\
\hline 6 & 110 & 135 & 190 & 204 & 265 & 202 & 146 \\
\hline 7 & 103 & 128 & 186 & 195 & 264 & 205 & 155 \\
\hline 8 & 102 & 130 & 188 & 210 & 252 & 212 & 162 \\
\hline 9 & 105 & 136 & 192 & 198 & 253 & 215 & 150 \\
\hline 10 & 105 & 134 & 179 & 205 & 255 & 208 & 157 \\
\hline Mean & 105.9 & 132 & 186.3 & 202 & 255.2 & 210 & 156 \\
SD & 3.63 & 5.05 & 5.39 & 8.45 & 6.21 & 4.96 & 8.96 \\
CV\% & 3.43 & 3.82 & 2.89 & 4.18 & 2.43 & 2.36 & 5.74 \\
\hline
\end{tabular}

Table 4 Productivity of 275 tex jute yarn at seven different flyer speeds (Draft 11, Twist 181 tpm)

\begin{tabular}{|c|c|c|c|c|c|c|c|}
\hline \multirow{2}{*}{$\begin{array}{c}\text { No. of } \\
\text { Exp. }\end{array}$} & \multicolumn{6}{|c|}{ Yarn productivity ( g/ spindle -hr ) through different flyer speeds ( rpm ) } \\
\cline { 2 - 8 } & 2900 & 3300 & 3600 & 4500 & 4700 & 4800 & 4850 \\
\hline 1 & 136 & 165 & 248 & 218 & 245 & 250 & 231 \\
\hline 2 & 130 & 180 & 240 & 220 & 235 & 252 & 226 \\
\hline 3 & 140 & 200 & 255 & 215 & 240 & 242 & 235 \\
\hline 4 & 125 & 170 & 265 & 235 & 250 & 255 & 236 \\
\hline 5 & 150 & 210 & 250 & 220 & 253 & 265 & 241 \\
\hline 6 & 117 & 199 & 254 & 230 & 235 & 255 & 229 \\
\hline 7 & 125 & 195 & 255 & 225 & 238 & 251 & 241 \\
\hline 8 & 135 & 207 & 247 & 232 & 245 & 253 & 227 \\
\hline 9 & 137 & 204 & 260 & 217 & 246 & 264 & 240 \\
\hline 10 & 135 & 170 & 246 & 218 & 231 & 233 & 231 \\
\hline Mean & 133 & 190 & 202 & 223 & 240 & 252 & 238 \\
SD & 9.21 & 17.04 & 7.30 & 7.03 & 6.20 & 9.41 & 5.71 \\
CV\% & 6.92 & 8.50 & 2.89 & 3.15 & 2.58 & 3.73 & 2.40 \\
\hline
\end{tabular}

Table 5 Flyer speed-Yarn Breakage/spindle-hr of 241 and 275 tex jute yarn

\begin{tabular}{|c|c|c|c|c|c|c|c|}
\hline $\begin{array}{c}\text { Flyer speed (rpm) } \\
\text { Number of yarn } \\
\text { breakages (241 tex) }\end{array}$ & 0.8 & 1.3 & 1.9 & 2.1 & 2.5 & 2.8 & 3.5 \\
\hline $\begin{array}{c}\text { Number of yarn } \\
\text { breakages (275 tex) }\end{array}$ & 0.5 & 0.9 & 1.3 & 1.8 & 1.9 & 2.0 & 3 \\
\hline
\end{tabular}

To determine the effect of flyer speed on twist of all jute yarn of 241 tex and 275 tex in the slip draft spinning frame, it is found that tpm varies with the variation of speeds. From table-1, it was noted that quality ratio gradually increased with the increasing of spindle speeds. At $4700 \mathrm{rpm}$, tpm was found 189 along with a quality ratio of $97.596 \%$.

From table-2, it was found that with the variation of speeds, tpm varied and followed an increasing trend. Moreover, it was shown that actual twist inserted in the yarn was reduced with the speeds, although a fixed twist was set. Here at $4800 \mathrm{rpm}$, quality ratio is also satisfactory i.e. $96.46 \%$. In table-3, it was noted that at different rpm, with increase of flyer speeds productivity increased gradually. The yarn spun at $4700 \mathrm{rpm}$ was found to possess 255.2-g/ spindle -hr with higher quality ratio of $96.64 \%$.

In table-4, it was also noted that at different rpm, with increase of flyer speeds productivity increased gradually. The yarn spun at $4800 \mathrm{rpm}$ was found to possess 252g/ spindle -hr with higher quality ratio of $96.46 \%$. In this experiment, effect of rpm 
variation on quality and productivity of yarn along with its different speeds was studied. From this study, it was noted that with the changes of speeds, quality and productivity were varied. Jute yarn of 241 tex and 275 tex spun at flyer speed of 4700 and $4800 \mathrm{rpm}$ with an actual optimum twist level of 189 tpm and 181 tpm respectively achieved the highest productivity. These are better result of yarn in comparison to others. From table5 , at 2900-rpm flyer speed the yarn breakage was 0.8 / spindle-hr and at $4850 \mathrm{rpm}$ the yarn breakages is 3.5/spindle-hr. for producing 241 tex jute yarn.

\section{Conclusions}

Almost all jute mills of Bangladesh have been slip draft spinning machine. Using proper flyer speed, which was found from the experiment, can use the machine in production of medium count jute yarn. The produced yarn can replace the synthetic/manmade fibre in the world textile market. The output of the research work has the identification of optimum machine parameters of hessian spinning frame for producing quality jute yarns having better physical properties. The findings have a direct impact on the jute industry and are able to produce better quality jute yarns by adopting the method suggested. Consequently, the use of jute fibre will be increased, which is bio-degrading and therefore environment friendly.

\section{References}

[1] A. Sivaramakrishnan,Vista Kumar N and Muthu Kumaraswamy P. "A study of spindles of various diameters”. The Indian textile journal, vol. 108, no. 2.1999. pp. 12-16.

[2] Miazi, M. O. G. An experimental investigation for optimization of machine parameters in a spinning machine for production of fine jute yarn. Ph. D. Thesis, BUET, Bangladesh. pp. 78-81, 93, 2002.

[3] Miazi, M. O. G. Adaptation of ring spinning in the flyer spinning machine for making fine jute yarn. M. Sc. Thesis, BUET, Bangladesh. pp. 18-2, 1997.

[4] Miazi, M. O. G. "Development of flyer spinning system by adapting ring spinning system" Bangladesh Journal of Jute and fibre Research. Vol. 13, 2000, pp. 61-68.

[5] Mahabubuzzaman, A.K.M. “A Comparative study on the Quality Control of Jute Yarn-Conventional drawing Method vs Modern Drawing Method”. Asian journal of Plant Sciences. Vol 1 No. 6, 2002, pp. 646-647.

[6] Ranjan, T.C. Handbook on Jute. 2nd Edition, Oxford and IBH pub, Co. 3rd edition, New Delhi, pp.22-31, 1985.

[7] Sheikh, M.A.S. "Fine Yarn spinning for jute fibre”. Bangladesh Journal of Jute and fibre Research. vol 7, no. 18, 1982, pp. 79-80.

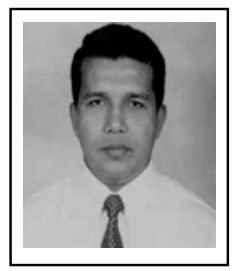

A. K. M. Mahabubuzzaman, Principal Scientific Officer, Department of Spinning, Mechanical Processing Division, Bangladesh Jute Research Institute has completed his Doctor of Philosophy from the Department of Physics, Jahangirnagar University, Savar, Dhaka. He got the Scholarship from Prime Minister's Research and Higher Studies Assistance Fund Program. He published fiftythree scientific papers in national and international journals and twelve popular articles in different magazines.

He focused about on the identification of optimum machine parameters of hessian spinning frame for producing quality jute yarns having better physical properties. The findings have a direct impact on the jute industry and are able to produce better quality jute yarns.

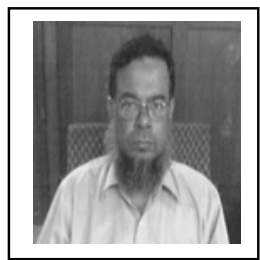

Md. Osman Ghani Miazi is the Chief Scientific Officer, Mechanical Processing Division, Bangladesh Jute Research Institute, Manik Mia Avenue, Dhaka, Bangladesh.

He receives B.Sc., M.Sc. and Ph.D. in Mechanical Engineering from BUET. He is engaged in Research and Development activities with natural and allied fibres for more than eighteen years in Bangladesh Jute Research Institute.

He has twenty-five national and international scientific papers and member, Institution of Engineers, Dhaka, Bangladesh.

$\mathrm{He}$ is also the General Secretary, Scientist Association, Bangladesh Jute Research Institute. He has four patents regarding research works. 